\title{
Health status, quality of life and socioeconomic situation of people with spinal cord injuries six years after discharge from a hospital in Bangladesh
}

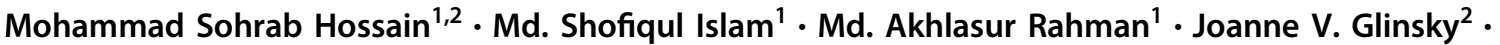 \\ Robert D. Herbert ${ }^{3} \cdot$ Stanley Ducharme ${ }^{4} \cdot$ Lisa A. Harvey $\mathbb{B}^{2}$
}

Published online: 20 February 2019

(c) International Spinal Cord Society 2019

\begin{abstract}
Study design Cross-sectional analysis of a mixed retrospective and prospective inception cohort study.

Objectives To determine health status, quality of life and socioeconomic situation of people with spinal cord injuries (SCI) 6 years after discharge from a hospital in Bangladesh.

Setting Bangladesh.

Methods All patients alive 6 years after discharge from a hospital in Bangladesh were interviewed using the SF12 health survey, the SCI Secondary Conditions Scale, the Centre for Epidemiologic Studies Depression Scale (CESD), and the participation in society items of World Health Organisation Disability Assessment Schedule (WHODAS 2.0). Additional questions determined participants' socioeconomic and employment status.

Results The cohort comprised 260 participants: 145 used wheelchairs for mobility and 115 were able to walk at discharge. The median (IQR) Mental and Physical Component scores for the SF12 were 54 (49-57) and 44 (40-51) points, respectively. The median scores for the SCI Secondary Conditions Scale, CESD and WHODAS 2.0 were 8 (4-13), 7 (4-13) and 12 (6-17) points, respectively. Fourteen percent of all participants and $23 \%$ of those who used wheelchairs had a pressure ulcer at the time of interview. Forty-four percent of participants were unemployed and $65 \%$ were living below the poverty line (median (IQR) income, USD 0 (0-91)) per month.

Conclusion Many people with SCI in Bangladesh are unemployed and living in poverty with a reduced quality of life and participation. Pressure ulcers are a common complication.
\end{abstract}

Supplementary information The online version of this article (https:// doi.org/10.1038/s41393-019-0261-9) contains supplementary material, which is available to authorized users.

Lisa A. Harvey

1.harvey@usyd.edu.au

1 Centre for the Rehabilitation of the Paralysed, Savar, Dhaka, Bangladesh

2 John Walsh Centre for Rehabilitation Research, Sydney Medical School/Northern, University of Sydney, Sydney, Australia

3 Neuroscience Research Australia (NeuRA), 139 Barker St, Randwick, NSW 2031, Australia

4 Boston Medical Center and Boston University School of Medicine, 725 Albany street, Boston, MA 02118, USA

\section{Introduction}

Many studies from high-income countries (HICs) have examined the physical, psychological, and social well-being of people following spinal cord injuries (SCI) [1-7]. However, there is very little information about these outcomes for people living with SCI in low- and middleincome countries (LMICs). Most of what has been described comes from small samples of convenience [8-12]. Such studies may be biased and therefore may not provide an accurate picture of the real situation. Nonetheless, they suggest that people living with SCI in LMICs face many problems and experience many complications. We sought to obtain a more accurate picture about the physical, psychological, and social well-being of people living with SCI in Bangladesh.

We previously identified all people who were discharged in 2011 with SCI from a large hospital in Bangladesh that 
specialises in the management of SCI: The Centre for the Rehabilitation of the Paralysed (CRP) [13]. This centre provides acute care and comprehensive rehabilitation services for people with SCI in Bangladesh regardless of income. Most patients are from a low socioeconomic background and are financially supported by CRP. In turn, CRP is supported by the government of Bangladesh, nongovernment organisations, and national and international donors. Those identified were assessed 2 years after discharge $[13,14]$. We found that many people were housebound, unemployed, living in poverty and experiencing pressure ulcers. They also experienced moderate rates of depression and reported limited quality of life. The purpose of this study was to follow-up this same cohort 6 years after discharge. We were particularly interested in determining health status, quality of life and socioeconomic situation.

\section{Methods}

This is a cross-sectional analysis of a mixed retrospective and prospective inception cohort study. Medical records were used to identify all patients admitted with SCI in 2011 to CRP. At that time details of participants were also collected including cause of injury (traumatic or non-traumatic), date of injury, type of injury (tetraplegia or paraplegia) and American Spinal Injury Association Impairment Scale (AIS; according to the International Standards for Neurological Classification of SCI). Those individuals who survived until discharge comprised the initial cohort. Details about those alive at 2 years have been previously published [13, 14]. In addition, we have published a paper focusing on survival 5 years after discharge [15]. The current paper describes the health status, quality of life and socioeconomic situation of those individuals alive 6 years after discharge.

Data were collected through telephone interviews conducted between November 2017 and May 2018, a median (IQR) of 6 years (6-7) since discharge. If the participant could not be contacted by telephone, a home visit was conducted and the interview was performed in person. All interviews and questionnaires were administered in Bangla. The questionnaires were translated by two local Bangladeshi healthcare professionals who were fluent in English, except the translation of the 12-item Short Form Health Survey (SF12) and the Centre for Epidemiological Studies Depression scale (CESD) which were provided to our team by other research groups who had back translated both questionnaires. We did not use the official World Health Organisation (WHO) Bangla version of the World Health Organisation Disability
Assessment Scale (WHODAS 2.0) because it was not available at the time of data collection. We did, however, subsequently cross-check our version with the official WHO Bangla version of WHOADS 2.0. The two versions were very similar although our version used less formal language in a few places. The following paragraphs outline the data that were collected.

\section{Socioeconomic situation}

Participants were asked about their current employment, income, marital status, carer arrangements, family size (total number of people living in the participant's household), current living arrangements (i.e., own house or rented), if they had conceived any children since their injury and if so how many.

\section{The Spinal Cord Injuries Secondary Conditions Scale (SCI-SCS)}

Data about secondary conditions were collected using the SCI-SCS. This is a standardised and validated 16-item questionnaire about complications such as pressure ulcers, respiratory problems, urinary and bladder incontinence, sexual dysfunction, autonomic dysreflexia, postural hypotension, spasticity, contractures and pain [16, 17]. Participants were asked to rate the 16 items according to their experiences over the last three months on a 4-point scale $(0$ 3 ) where a score of zero reflects "Not experienced in the last 3 months or not a significant problem" and a score of four reflects "Severe or chronic problem". The scores for each item were totalled and expressed as a percentage of a total possible score of 48 points. A higher score reflects more complications.

\section{Pressure ulcers}

Participants were asked if they currently had a pressure ulcer. The severity of the pressure ulcer was captured in one of the questions of the SCI-SCS.

\section{The World Health Organisation Disability Assessment Scale (WHODAS 2.0)}

Community participation was captured using the participation in society items of the self-administered version of the WHODAS 2.0. The WHODAS 2.0 has been extensively used in people with SCI [18]. It has good validity and reliability [18, 19] and has been previously used in Bangladesh [10]. It comprises eight questions that seek to quantify how much people's disabilities affect their lives in the last 30 days. Each question is answered on a 5 -point scale $(1=$ 'none', $2=$ 'mild', 3 
$=$ 'moderate', $4=$ 'severe' and $5=$ 'extreme or cannot do'). Scores are tallied and expressed out of a total possible score of 40 points where a higher score reflects extreme problems associated with all aspects of community participation [19].

\section{The Short Form Health Survey (SF-12)}

Quality of life was assessed with the SF-12 [20]. This consists of 12 questions each graded on a 2- to 6-point scale. The Physical Component Summary and the Mental Component Summary scores were obtained using a standard algorithm developed from a US general population unadjusted for age and gender. Scores were standardised so that a score of 50 represents average functioning with a SD of 10 (that is, a score of 30 is equivalent to the lowest $2.5 \%$ of the American population). Higher scores reflect a better quality of life. The SF12 has been used in Bangladesh with other clinical populations [20].

\section{The Centre for Epidemiological Studies Depression scale (CESD)}

Depressive disorders were measured with the CESD. This scale is widely used to assess symptoms of depression experienced over the preceeding two weeks as defined by the American Psychiatric Association Diagnostic and Statistical Manual [21-23]. The CESD comprises 20 questions each scored on a 4-point scale anchored at one end with 'rarely or none of the time' and at the other end with 'most or all of the time.' The highest possible score of 60 reflects a severe depressive disorder. Participants with scores of 16 or more are classified as having subthreshold depressive symptoms, possible depressive disorders, probable depressive disorders or major depressive disorders according to an algorithm. In addition, scores for individual questions are used to determine whether participants have symptoms in the nine different groups of sadness, loss of interest, appetite, sleep, thinking, guilt, tired, movement or suicidal ideation.

\section{Additional questions}

Participants were also asked two additional questions to capture their participation. The questions were:

(i) Have you got out of your bed in the last week (do not include getting out of bed for the toilet or shower)? If so, on how many days did you get out of bed?

(ii) Have you been out of the bounds of your home in the last week? If so, on how many days did you go out of the bounds of your home?

\section{Analysis}

A descriptive analysis was conducted. Continuous data were described as means (standard deviation, SD) or medians (interquartile ranges, IQR) if skewed. Count data were expressed as proportions. All data were stratified by mobility status at discharge.

\section{Results}

Three hundred and forty-five patients were discharged from CRP in 2011 with SCI. Eighty-one had died by the time of interview leaving 264 people alive. Of these, three were unable to be located and one was unable to speak and was therefore not interviewed. Therefore, the final cohort that was interviewed was 260 participants representing $98 \%$ of those discharged and still alive at 6 years. Table 1 provides demographic details of the 260 participants: 145 participants used wheelchairs for mobility and 115 were able to walk at discharge. The median (IQR) age at the time of injury was 30 years (22-40). One hundred and fifty-four (59\%) had traumatic paraplegia and 95 (37\%) participants had traumatic tetraplegia.

Table 2 provides details of the socioeconomic situations of participants. Most participants were married prior to injury and were still married 6 years after discharge although, amongst those who used wheelchairs at discharge, there was a small reduction in the proportion of participants who were married from injury to 6 years (from 68 to 55\%). Prior to injury, $168(65 \%)$ participants were the main income earners for their families but at 6 years only 89 (34\%) participants were the main income earners most of whom were walking at discharge. The median (IQR) income per month of all participants at 6 years was USD 0 $(0-91) ; 65 \%$ of all participants and $75 \%$ of those who used wheelchairs were living below the poverty line 6 years after discharge (the poverty line for Bangladesh is less than $\$ 60$ per month as defined by WHO [24]).

Table 3 shows the results of the SCI-SCS, WHODAS 2.0, SF12, CESD, presence of pressure ulcers and the two additional questions about participation. The median (IQR) scores for the SCI-SCS, and WHODAS 2.0 were 8 points (4-13) and 12 points (6-17), respectively. The median (IQR) scores for the Physical and Mental Components of the SF-12 were 44 points $(40-51)$ and 54 points (49-57), respectively. The median (IQR) scores for the CESD was 7 points (4-13). The CESD results are also expressed according to the number of people exhibiting symptoms of depression in each of the nine different groups and the number of people with possible, probable and major depressive episodes. Thirty-five participants (14\%) had pressure ulcers at the time of interview. Figures 1 and 2 and 
Table 1 Characteristics of all participants $(n=260)$. Data are means (SDs) except where indicated otherwise

\begin{tabular}{|c|c|c|c|}
\hline & $\begin{array}{l}\text { All participants } \\
(n=260)\end{array}$ & $\begin{array}{l}\text { Walking at discharge } \\
(n=115)\end{array}$ & $\begin{array}{l}\text { Using a wheelchair at } \\
\text { discharge }(n=145)\end{array}$ \\
\hline \multicolumn{4}{|l|}{ Gender, $n(\%)$} \\
\hline Male & $231(89 \%)$ & $98(85 \%)$ & $133(92 \%)$ \\
\hline Female & $29(11 \%)$ & $17(15 \%)$ & $12(8 \%)$ \\
\hline $\begin{array}{l}\text { Age at the time of injury } \\
\text { (years), median (IQR) }\end{array}$ & $30(22-40)$ & $35(25-45)$ & $28(20-36)$ \\
\hline \multicolumn{4}{|l|}{ AIS classification, $n(\%)$} \\
\hline A & $116(45 \%)$ & $9(8 \%)$ & $107(74 \%)$ \\
\hline $\mathrm{B}$ & $61(24 \%)$ & $34(30 \%)$ & $27(19 \%)$ \\
\hline $\mathrm{C}$ & $32(12 \%)$ & $24(21 \%)$ & $8(6 \%)$ \\
\hline $\mathrm{D}$ & $48(19 \%)$ & $45(39 \%)$ & $3(2 \%)$ \\
\hline $\mathrm{E}$ & $3(1 \%)$ & $3(3 \%)$ & - \\
\hline \multicolumn{4}{|l|}{ Type of injury, $n(\%)$} \\
\hline Paraplegia, $n(\%)$ & $164(63 \%)$ & $67(58 \%)$ & $97(67 \%)$ \\
\hline Traumatic & $154(59 \%)$ & $59(51 \%)$ & $95(67 \%)$ \\
\hline Non-traumatic & $10(4 \%)$ & $8(7 \%)$ & $2(1 \%)$ \\
\hline Tetraplegia, $n(\%)$ & $96(37 \%)$ & $48(42 \%)$ & $48(33 \%)$ \\
\hline Traumatic & $95(37 \%)$ & $48(42 \%)$ & $47(32 \%)$ \\
\hline Non-traumatic & $1(1 \%)$ & - & $1(1 \%)$ \\
\hline \multicolumn{4}{|l|}{ Others, median (IQR) } \\
\hline Follow-up time (years) & $6(6-7)$ & $6(6-7)$ & $6(6-7)$ \\
\hline $\begin{array}{l}\text { Time between injury and } \\
\text { admission (days) }\end{array}$ & $12(4-35)$ & $9(3-25)$ & $15(4-48)$ \\
\hline $\begin{array}{l}\text { Length of hospital } \\
\text { admission (months) }\end{array}$ & $3(2-4)$ & $2(2-3)$ & $4(3-5)$ \\
\hline
\end{tabular}

the Supplementary files show the responses to each of the questions comprising the WHODAS 2.0 and the SCISCS for those who were walking at discharge and those who were using a wheelchair at discharge.

\section{Discussion}

The results of this study are valuable because most of what we know about the health status, quality of life and socioeconomic situation of people with SCI living in LMICs come from cross-sectional studies of samples of convenience [8-12]. These types of studies are vulnerable to selection bias. The cohort in this study is unique because it is a representative sample of all patients admitted to a large hospital in Bangladesh with very little loss to follow-up 6 years after discharge. The most important findings from this study are that people surviving for 6 years experienced high levels of unemployment and poverty, and that pressure ulcers are prevalent.

At the time of interview, 35 participants (14\%) had a pressure ulcer (Table 3). Of these, $22(9 \%)$ reported that pressure ulcers had been a moderate or chronic problem in the preceding 3 months (Fig. 2). All but one participant with a pressure ulcer used a wheelchair for mobility at discharge. These findings probably underestimate the real problems that pressure ulcers pose in LMICs [7, 25, 26] because those who had already died $(n=81)$ or were not interviewed for other reasons $(n=4)$ may have been more likely to have experienced pressure ulcers had they been alive and included $[13,14]$. Our findings may also not be reflective of the severity of the problem for most people living with SCI in LMICs because the participants in our cohort may have been better able to manage skin problems than most. Unlike many individuals from LMICs, the participants in our cohort had received comprehensive rehabilitation including education about skin care and provision of equipment for the prevention of pressure ulcers.

Complications other than pressure ulcers were less common (Fig. 2). Only $15 \%$ of participants reported muscle spasms as a moderate or chronic problem even though this was the most commonly reported problem on the SCI-SCS. This is a lower rate of complications than reported in comparable studies from LMICs [5, 26, 27] and even lower than reported from HICs [3, 7, 28-30]. Similarly, none of the participants in our cohort reported injuries secondary to loss of sensation even though others have found that up to $50 \%$ of participants experience this complication [29, 30]. 
Table 2 Financial and social situation for all participants $(n=260)$

\begin{tabular}{|c|c|c|c|}
\hline & $\begin{array}{l}\text { All participants } \\
(n=260)\end{array}$ & $\begin{array}{l}\text { Walking at discharge } \\
(n=115)\end{array}$ & $\begin{array}{l}\text { Using a wheelchair at } \\
\text { discharge }(n=145)\end{array}$ \\
\hline \multicolumn{4}{|c|}{ Marital status at time of injury, $n(\%)$} \\
\hline Married & $188(72 \%)$ & $89(77 \%)$ & $99(68 \%)$ \\
\hline Not married & $69(27 \%)$ & $23(20 \%)$ & $46(32 \%)$ \\
\hline Divorced $^{\mathrm{a}}$ & $1(1 \%)$ & $1(1 \%)$ & - \\
\hline \multicolumn{4}{|l|}{ Marital status at 6 years, $n(\%)$} \\
\hline Married & $171(65 \%)$ & $91(79 \%)$ & $80(55 \%)$ \\
\hline Not married & $72(28 \%)$ & $20(17 \%)$ & $52(36 \%)$ \\
\hline Divorced $^{\mathrm{a}}$ & $15(6 \%)$ & $3(3 \%)$ & $12(8 \%)$ \\
\hline Widowed & $2(1 \%)$ & $1(1 \%)$ & $1(1 \%)$ \\
\hline \multicolumn{4}{|l|}{ Place of residence, $n(\%)$} \\
\hline Urban/city & $20(8 \%)$ & $12(10 \%)$ & $8(5 \%)$ \\
\hline Rural/village & $240(92 \%)$ & $103(90 \%)$ & $137(95 \%)$ \\
\hline \multicolumn{4}{|l|}{ Work status at 6 years, $n(\%)$} \\
\hline $\begin{array}{l}\text { Full time employed ( }>30 \mathrm{~h} \\
\text { per week) }\end{array}$ & $102(39 \%)$ & $51(44 \%)$ & $51(35 \%)$ \\
\hline $\begin{array}{l}\text { Part time employed }(<30 \mathrm{~h} \\
\text { per week })\end{array}$ & $21(8 \%)$ & $11(10 \%)$ & $10(7 \%)$ \\
\hline Retired & $2(1 \%)$ & $2(2 \%)$ & - \\
\hline Unemployed & $115(44 \%)$ & $38(33 \%)$ & $77(53 \%)$ \\
\hline Home duties & $11(4 \%)$ & $8(7 \%)$ & $3(2 \%)$ \\
\hline Student & $9(4 \%)$ & $5(4 \%)$ & $4(3 \%)$ \\
\hline $\begin{array}{l}\text { Main income earner prior to } \\
\text { injury, } n(\%)\end{array}$ & $168(65 \%)$ & $76(66 \%)$ & $92(63 \%)$ \\
\hline $\begin{array}{l}\text { Main income earner at } 6 \text { years, } \\
n(\%)\end{array}$ & $89(34 \%)$ & $53(46 \%)$ & $35(24 \%)$ \\
\hline $\begin{array}{l}\text { Participants' income }(\$) \text { per } \\
\text { month prior to injury, median } \\
\text { (IQR) }\end{array}$ & $78(39-117)^{\mathrm{b}}$ & $78(39-130)$ & $65(39-104)^{\mathrm{c}}$ \\
\hline $\begin{array}{l}\text { Participants' income }(\$) \text { per } \\
\text { month at } 6 \text { years, median } \\
(\mathrm{IQR})\end{array}$ & $0(0-91)$ & $52(0-130)$ & $0(0-65)$ \\
\hline $\begin{array}{l}\text { Participants in poverty prior to } \\
\text { injury, } n(\%)\end{array}$ & $84(32 \%)$ & $36(31 \%)$ & $48(33 \%)$ \\
\hline $\begin{array}{l}\text { Participants in poverty at } \\
6 \text { years, } n(\%)\end{array}$ & $168(65 \%)$ & $60(52 \%)$ & $108(75 \%)$ \\
\hline \multicolumn{4}{|l|}{ Main carer at 6 years, $n(\%)$} \\
\hline Spouse & $157(60 \%)$ & $79(69 \%)$ & $78(54 \%)$ \\
\hline Parent & $63(24 \%)$ & $14(12 \%)$ & $49(34 \%)$ \\
\hline Others & $40(16 \%)$ & $22(19 \%)$ & $18(12 \%)$ \\
\hline $\begin{array}{l}\text { Number of people per } \\
\text { household at } 6 \text { years, median } \\
\text { (IQR) }\end{array}$ & $4(3-5)$ & $4(3-5)$ & $4(3-5)$ \\
\hline \multicolumn{4}{|c|}{ Number of participants conceiving children after SCI, $n(\%)$} \\
\hline One child & $25(10 \%)$ & $20(17 \%)$ & $5(3 \%)$ \\
\hline Two children & $6(2 \%)$ & $6(5 \%)$ & - \\
\hline
\end{tabular}

${ }^{\mathrm{a}}$ These numbers only include those who declared that they were divorced. It does not include those who were living apart from their spouses

${ }^{\mathrm{b}} n=252$

${ }^{c} n=141$ 
Table 3 Results of questionnaires for all participants $(n=260)$

\begin{tabular}{|c|c|c|c|}
\hline & $\begin{array}{l}\text { All participants } \\
(n=260)\end{array}$ & $\begin{array}{l}\text { Walking at discharge } \\
(n=115)\end{array}$ & $\begin{array}{l}\text { Using a wheelchair at } \\
\text { discharge }(n=145)\end{array}$ \\
\hline $\begin{array}{l}\text { SCI Secondary Conditions Scale } \\
(\%) \text {, median (IQR) }\end{array}$ & $8(4-13)$ & $4(2-8)$ & $10(8-15)$ \\
\hline $\begin{array}{l}\text { WHODAS } 2.0 \text { - participation in } \\
\text { society items, median (IQR)/40 } \\
\text { pts }\end{array}$ & $12(6-17)$ & $5(0-13)$ & $15(10-18)$ \\
\hline \multicolumn{4}{|l|}{ SF12, median (IQR) } \\
\hline Mental & $54(49-57)$ & $54(52-55)$ & $54(45-57)$ \\
\hline Physical & $44(40-51)$ & $51(44-52)$ & $41(38-44)$ \\
\hline \multicolumn{4}{|l|}{ CESD, median (IQR) } \\
\hline Total score, /60 pts & $7(4-13)$ & $5(3-8)$ & $9(5-17)$ \\
\hline \multicolumn{4}{|c|}{ Symptoms group of the CESD, $n(\%)$} \\
\hline Sadness & $23(9 \%)$ & $7(6 \%)$ & $16(11 \%)$ \\
\hline Loss of interest & $18(7 \%)$ & $3(3 \%)$ & $15(10 \%)$ \\
\hline Loss of appetite & $3(1 \%)$ & - & $3(2 \%)$ \\
\hline Sleep & $3(1 \%)$ & $1(1 \%)$ & $2(1 \%)$ \\
\hline Thinking & $3(1 \%)$ & - & $3(2.1 \%)$ \\
\hline Guilt & $9(4 \%)$ & $3(3 \%)$ & $6(4.1 \%)$ \\
\hline Tired & $38(15 \%)$ & $9(8 \%)$ & $29(20 \%)$ \\
\hline Movement & $20(8 \%)$ & $6(5 \%)$ & $14(10 \%)$ \\
\hline Suicidal ideation & $6(2 \%)$ & $3(3 \%)$ & $3(2 \%)$ \\
\hline \multicolumn{4}{|c|}{ Depression subdomain scores, $n(\%)$} \\
\hline Total score $>15$ points & $54(21 \%)$ & $12(10 \%)$ & $42(29 \%)$ \\
\hline $\begin{array}{l}\text { Possible major depressive } \\
\text { episode }\end{array}$ & $5(2 \%)$ & $1(1 \%)$ & $4(3 \%)$ \\
\hline $\begin{array}{l}\text { Probable major depressive } \\
\text { episode }\end{array}$ & $7(3 \%)$ & $2(2 \%)$ & $5(3 \%)$ \\
\hline $\begin{array}{l}\text { Meets criteria for major } \\
\text { depressive episode }\end{array}$ & $6(2 \%)$ & $2(2 \%)$ & $4(3 \%)$ \\
\hline Pressure ulcer, $n(\%)$ & $35(14 \%)$ & $1(1 \%)$ & $34(23 \%)$ \\
\hline \multicolumn{4}{|l|}{ Out of bed } \\
\hline $\begin{array}{l}\text { Number of people out of bed, } \\
\text { preceding week, } n(\%)\end{array}$ & $256(99 \%)$ & $114(99 \%)$ & $142(98 \%)$ \\
\hline $\begin{array}{l}\text { Number of days out of bed, } \\
\text { preceding week, median } \\
\text { (IQR) }\end{array}$ & $7(7-7)$ & $7(7-7)$ & $7(7-7)$ \\
\hline \multicolumn{4}{|l|}{ Out of home } \\
\hline $\begin{array}{l}\text { Number of people out of } \\
\text { home, preceding week, } n(\%)\end{array}$ & $236(91 \%)$ & $113(98 \%)$ & $123(85 \%)$ \\
\hline $\begin{array}{l}\text { Number of days out of the } \\
\text { home, preceding week, } \\
\text { median (IQR) }\end{array}$ & $7(7-7)$ & $7(7-7)$ & $7(3-7)$ \\
\hline
\end{tabular}

CESD Centre for Epidemiologic Studies Depression Scale, IQR interquartile range, $p t s$ points, SCI spinal cord injury, WHODAS 2.0 World Health Organisation Disability Assessment Scale 2.0
These differences may in part reflect the problems of relying on self-report over the telephone. Alternatively, they may reflect the characteristics of the study participants. For instance, the two studies from LMICs included participants soon after injury before those at high risk of complications had died, and most studies (including those from HICs) have high dropout rates [9].
Participation (defined here as involvement in life situations [31]) was captured through the participation in society items of the WHODAS 2.0. The median (IQR) score was $12 / 40$ points (6-17) indicating that participants had some problems with participation, but the level of problems that participants experienced was not as high as expected. For example, these scores are lower than those reported in 


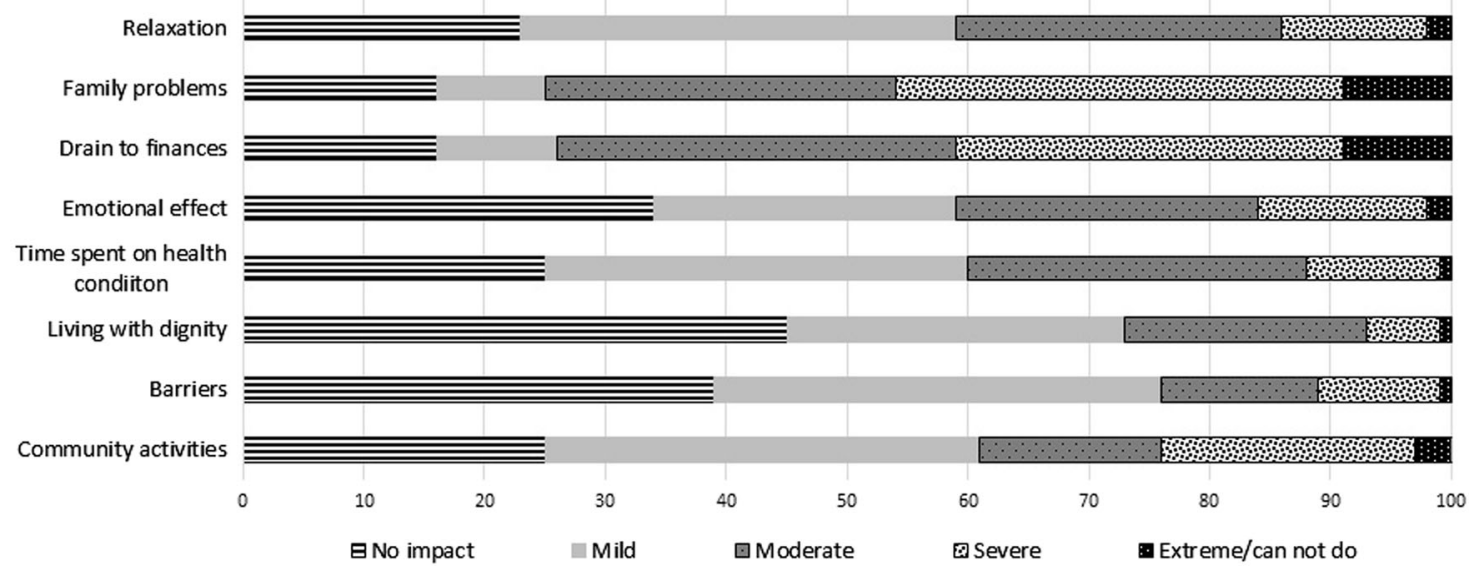

Fig. 1 Results of the participation in society items of the WHODAS 2.0 for all participants $(n=260)$. The $x$-axis shows the percentage of responses and the $y$-axis shows each of the items on the WHODAS 2.0 (see supplementry files for data divided by walking and using a wheelchair at discharge)

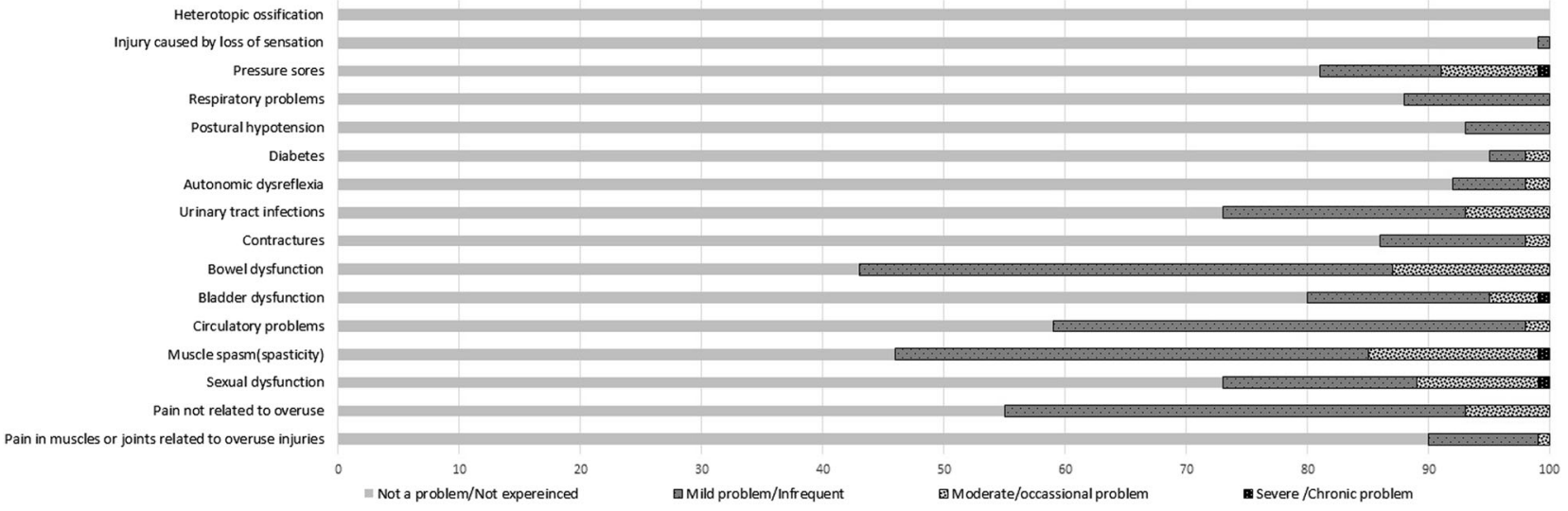

Fig. 2 Results of Spinal Cord Secondary Conditions Scale for all participants $(n=260)$. The $x$-axis shows the percentage of responses and the $y$ axis shows each of the items on the Spinal Cord Injury Secondary Conditions Scale (see supplementary files for data divided by walking and using a wheelchair at discharge)

comparable studies from Canada (mean $=14$ points) [32] and Taiwan (mean $=23$ points) [19]. Not surprisingly, those in our cohort who used wheelchairs at discharge reported less participation on the WHODAS 2.0 (median 15: IQR 10-18) than those who were walking at discharge (median 5: IQR 0-13) (Table 3). Two SF-12 questions also reflect participation; one asks participants if their health limits their ability to work and the other asks if health interferes with social activities. Thirty-five percent and $97 \%$ of participants who used wheelchairs indicated that they experienced limitations in these two areas, respectively. These findings were mirrored in the responses to the question about how often participants left their homes in the preceding week. Even though the median for the two groups was 7 days, suggesting good participation, the lower end of the IQR for those who used wheelchairs indicated that $25 \%$ of this group did not leave their homes more than three times in the preceding week (Table 3). These data may overestimate participation and underestimate the extent of social isolation experienced by people living with SCI in LMICs because when participants were asked if they moved outside their homes, they did not distinguish between just moving (or being moved) outside the front door of their homes and moving further afield into their communities. The results may therefore largely reflect how often people moved from inside their homes to a cooler position outside their homes during the day. Nonetheless, our data do not negate the obvious and pressing need to improve wheelchair access in these communities $[8,33,34]$ as recommended in the WHO international perspectives on SCI report [35] and in The Convention on the Rights of Persons with Disabilities [36].

Limited participation was accompanied by poor scores on the SF-12 but these scores were not as low as one might expect. The poorest scores were for the physical domain in those who used wheelchairs (median 41: IQR 38-44) (Table 3). The scores for the physical domain were lower than the scores for the mental domain for both groups. 
While $15 \%$ and $17 \%$ of participants indicated on the SF-12 that they accomplished less than they would like or did not perform work or activities as carefully as usual due to emotional problems (such as feeling depressed or anxious), respectively, they displayed generally low levels of depression with low CESD scores (median CESD score of 7/60 points; IQR 4-13) (Table 3). However, some participants showed signs of sadness (9\%), loss of interest $(7 \%)$, tiredness $(15 \%)$ and agitation $(8 \%)$ on these CESD symptom groups. In addition, a small number of participants had major depression $(2 \%)$, probable depression $(3 \%)$ or possible depression (2\%) according to the American Psychiatric Association Diagnostic and Statistical Manual. Nonetheless, our findings on depression contrast the findings from HICs that report much higher rates of depression [4, 21].

A notable and alarming finding from the WHODAS 2.0 data was that $57 \%$ and $53 \%$ of participants who used wheelchairs at discharge reported that their SCI had created "severe" or "extreme" family problems and stress on their family's finances, respectively (Supplementary File 1), with $84 \%$ of participants reliant on spouses or parents as their main carers (Table 2). These findings may partly reflect that most were young married men living in large families (median number of people per household, 4: IQR 3-5) in which $65 \%$ were the main income earners prior to injury. At 6 years only $34 \%$ of participants were the main income earners and $65 \%$ lived below the poverty line (equivalent to USD 60 per month or USD 1.97 per day [24]). Not surprisingly individual income of participants fell from a median (IQR) of USD 78 (39-117) per month prior to injury to USD 0 (0-91) 6 years after injury. These data highlight the far-reaching implications of SCI for people living in LMICs and their families, and the pressing need for a focus on employment to reduce the poverty associated with SCI [36-39]. Similar findings have been reported by others who have highlighted the need for interest-free loans for people with SCI in Bangladesh [40]. The low rates of employment may also reflect discrimination and biases against people with disabilities.

The results presented here at 6 years after discharge were largely similar to the results from the same cohort 2 years after discharge [14]. For example, the median (IQR) SCISCS score was 8 (4-13) at 2 years and 10 (6-17) at 6 years. Similarly, the proportion of participants with pressure ulcers were similar (14 and 16\%). However, there were some improvements in quality of life with a mean (SD) mental SF12 score at 2 years of 33.9 (6.4) versus mean (IQR) score at 6 years of 54 (49-57) points. Similarly, the levels of depression decreased over time from a median (IQR) of 10 (8-14) to 7 (4-13) points on the CESDS. The only marked difference was with the WHODAS 2.0 scores. At 2 years the median (IQR) WHODAS 2.0 was $24(20-26)$ and at 6 years it was 12 (6-17) points, reflecting increased participation with time.

The main limitation of our study was that most data were collected through self-reported questionnaires administered over the telephone. It would have been better to have interviewed participants in their homes and verified answers in a more objective way. For instance, complications could have been better assessed through a physical examination, and participants' socioeconomic situation could have been more accurately determined through a home visit. However, sending staff all over Bangladesh is costly and expensive, particularly given the problems with travelling to rural locations. In addition, there are advantages to exploring participants' perspectives regardless of whether they align with objective assessments.

Another limitation of our study was the reliance on questionnaires developed for HICs. This was particularly problematic for the SF-12 because the scoring uses normative data from the US which may compromise the validity of the findings [41]. In addition, some questions from some of the assessments were not appropriate for all participants and some questions may have been misunderstood. For example, the SCS-SCI contains a question about sexuality but the question is ambiguous, and hence it is unclear whether it refers to sexual dysfunction or sexual dissatisfaction. Similarly, one of the questions in the SF-12 asks participants if they accomplished less than they would like. Eighty-five percent of participants answered "no". This is an unexpected finding and suggests a problem with the question for the Bangladeshi context. In addition, there are issues around cultural norms which may have discouraged participants from revealing their true experiences particularly for questions related to sexuality and depression [42]. Many of these and related issues require further exploration with unambiguous language that takes cultural norms into consideration.

All of our results may have been influenced by survival bias. That is, those who died by 6 years $(n=81)$ may not have been a random subgroup of the original cohort and may have scored differently to the others on all outcomes had they survived. Studies from HICs may not be so vulnerable to this type of bias because they have lower rates of mortality, and different underlying socioeconomic causes of premature death following SCI. Similarly, there may be fundamental differences in the neurological status of our cohort than those from HICs. For example, our cohort is younger and less disabled than most [15]. These two factors make comparisons between our results and those from HICs difficult, and may in part explain some of our surprising results particularly for depression and quality of life. Alternatively, the surprising results may reflect cultural differences between HICs and LMICs. Bangladesh is a country in which most people have strong family support 
and religious beliefs. In addition, there are many other cultural factors that feed into people's interpretation and acceptance of their situations. For example, our impression is that people living in rural Bangladesh are often very accepting of a change in circumstances. These factors together may make people living with SCI in Bangladesh more resilient than is often assumed and may help maintain quality of life and help protect against depression after SCI. This hypothesis is highly speculative but other researchers working in LMICs have also noted that those with severe injuries, disabilities and disadvantage do not exhibit the high levels of depression and low levels of quality of life that would be expected from similar cohorts in HICs [9, 43]. These researchers have suggested that cultural, religious and family differences between LMICs and HICs could explain these findings [35, 44, 45]. This interpretation also aligns with the beliefs of some cross-cultural psychologists who argue that quality of life and other aspects of subjective well-being are highly influenced by culture [42, 46]. We acknowledge, however that this interpretation is not easily reconciled with the observation of high rates of depression following the onset of leprosy and stroke in Bangladesh [47], and that there may be many other explanations including problems with the scales used to assess quality of life and depression. Clearly, more work is required in this area and it is important that conclusions regarding depression in LMICs are based on additional studies which consider all factors.

This study provided a snapshot of the health status, quality of life and socioeconomic situation of a representative sample of people living with SCI 6 years after discharge from a hospital in Bangladesh. The key findings from this study are that these people experience high levels of unemployment and poverty. Quality of life is reduced and there is some depression. Participation is restricted by the physical environment, and pressure ulcers are a common complication. It is hoped that this study will draw additional attention to the needs of people with SCI living in LMICs. Key issues that need addressing are increased opportunities for employment, better wheelchair access in communities, and models of care to help manage pressure ulcers in the community.

\section{Data archiving}

All reasonable requests for access to the original data upon which this paper is based will be considered.

Acknowledgements We acknowledge staff members and patients of the Centre for the Rehabilitation of the Paralysed.

Author contributions MSH conceived the research question, designed the study, collected the data, analysed the data, interpreted the data and wrote the manuscript. LAH and RDH conceived the research question, designed the study, analysed the data, interpreted the data and wrote the manuscript. MSI and MAR collected the data and contributed to the research question, the design of the study, the interpretation of the data and the write-up of the manuscript. JVG and $\mathrm{SD}$ contributed to the interpretation of the data and the write-up of the manuscript.

Funding This work was supported by Bridging Support Grants from The University of Sydney [171654 and 2013-00033].

\section{Compliance with ethical standards}

Conflict of interest The authors declare that they have no conflict of interest.

Statement of ethics The study received ethical approval (CRP-R\&E0401-218) from CRP and was conducted in accordance with the Declaration of Helsinki. Participants provided informed consent. We certify that all applicable institutional and governmental regulations concerning the ethical use of human volunteers were followed during the course of this research.

Publisher's note: Springer Nature remains neutral with regard to jurisdictional claims in published maps and institutional affiliations.

\section{References}

1. Pagliacci MC, Franceschini M, Di Clemente B, Agosti M, Spizzichino L, Gisem. A multicentre follow-up of clinical aspects of traumatic spinal cord injury. Spinal Cord. 2007;45:404-10.

2. Post MW, van Leeuwen CM. Psychosocial issues in spinal cord injury: a review. Spinal Cord. 2012;50:382-9.

3. McKinley WO, Jackson AB, Cardenas DD, DeVivo MJ. Longterm medical complications after traumatic spinal cord injury: a regional model systems analysis. Arch Phys Med Rehabil. 1999;80:1402-10.

4. Krause JS, Saunders LL. Health, secondary conditions, and life expectancy after spinal cord injury. Arch Phys Med Rehabil. 2011;92:1770-5.

5. Khazaeipour Z, Taheri-Otaghsara SM, Naghdi M. Depression following spinal cord injury: its relationship to demographic and socioeconomic indicators. Top Spinal Cord Inj Rehabil. 2015;21:149-55.

6. Strauss D, DeVivo M, Shavelle R, Brooks J, Paculdo D. Economic factors and longevity in spinal cord injury: a reappraisal. Arch Phys Med Rehabil. 2008;89:572-4.

7. Zakrasek EC, Creasey G, Crew JD. Pressure ulcers in people with spinal cord injury in developing nations. Spinal Cord. 2015;53:713.

8. Ahmed N, Quadir MM, Rahman MA, Alamgir H. Community integration and life satisfaction among individuals with spinal cord injury living in the community after receiving institutional care in Bangladesh. Disabil Rehabil. 2018;40:1033-40.

9. Islam MS, Jahan H, Hossain MS, Patwary MFK. Quality of life among persons with paraplegic spinal cord injury. DCID. 2016;27:102-117.

10. Kader M, Perera KP, Hossain MS, Islam R. Socio-demographic and injury-related factors contributing to activity limitations and participation restrictions in people with spinal cord injury in Bangladesh. Spinal Cord. 2017;56:239-46.

11. Kumar N, Gupta B. Effect of spinal cord injury on quality of life of affected soldiers in India: a cross-sectional study. Asian Spine J. 2016;10:267-75. 
12. Scovil CY, Ranabhat MK, Craighead IB, Wee J. Follow-up study of spinal cord injured patients after discharge from inpatient rehabilitation in Nepal in 2007. Spinal Cord. 2012;50:232-7.

13. Hossain MS, Rahman MA, Herbert RD, Quadir MM, Bowden JL, Harvey LA. Two-year survival following discharge from hospital after spinal cord injury in Bangladesh. Spinal Cord. 2016;54:132-6.

14. Hossain MS, Rahman MA, Bowden JL, Quadir MM, Herbert RD, Harvey LA. Psychological and socioeconomic status, complications and quality of life in people with spinal cord injuries after discharge from hospital in Bangladesh: a cohort study. Spinal Cord. 2016;54:483-9.

15. Hossain MS, Harvey LA, Islam MS, Rahman MA, Glinsky JV, Herbert RD. A prediction model to identify people with spinal cord injury who are at high risk of dying within 5 years of discharge from hospital in Bangladesh. Spinal Cord. 2018. https:// doi.org/10.1038/s41393-018-0211-y. [Epub ahead of print].

16. Arora M, Harvey LA, Lavrencic L, Bowden JL, Nier L, Glinsky $\mathrm{JV}$, et al. A telephone-based version of the spinal cord injurysecondary conditions scale: a reliability and validity study. Spinal Cord. 2016;54:402-5.

17. Kalpakjian CZ, Scelza WM, Forchheimer MB, Toussaint LL. Preliminary reliability and validity of a spinal cord injury secondary conditions scale. J Spinal Cord Med. 2016;30:131-9.

18. Üstün TBKN, Chatterji S, Rehm J. Measuring health and disability: manual for WHO Disability Assessment Schedule (WHODAS 2.0). Geneva, Switzerland; 2010.

19. Chi WC, Chang KH, Escorpizo R, Yen CF, Liao HF, Chang FH, et al. Measuring disability and its predicting factors in a large database in Taiwan using the World Health Organization Disability Assessment Schedule 2.0. Int J Environ Res Public Health. 2014;11:12148-61.

20. Islam N, Khan IH, Ferdous N, Rasker JJ. Translation, cultural adaptation and validation of the English "Short form SF 12v2" into Bengali in rheumatoid arthritis patients. Health Qual Life Outcomes. 2017;15:109.

21. Jorgensen S, Ginis KA, Iwarsson S, Lexell J. Depressive symptoms among older adults with long-term spinal cord injury: associations with secondary health conditions, sense of coherence, coping strategies and physical activity. J Rehabil Med. 2017;49:644-51.

22. Cook KF, Kallen MA, Bombardier C, Bamer AM, Choi SW, Kim $\mathrm{J}$, et al. Do measures of depressive symptoms function differently in people with spinal cord injury versus primary care patients: the CES-D, PHQ-9, and PROMIS ${ }^{\circ}$-D. Qual Life Res. 2017;26:139-48.

23. American Psychiatric Assoc United States of America. Diagnostic and statistical manual of mental disorders (5th edition) - DSM-5. 2013.

24. The World Bank. Poverty and equity data portal. http://povertyda ta.worldbank.org/poverty/home/. Accessed on 5 Oct 2018.

25. Kovindha A, Kammuang-Lue P, Prakongsai P, Wongphan T. Prevalence of pressure ulcers in Thai wheelchair users with chronic spinal cord injuries. Spinal Cord. 2015;53:767-71.

26. Lofvenmark I, Wikmar LN, Hasselberg M, Norrbrink C, Hultling C. Outcomes 2 years after traumatic spinal cord injury in Botswana: a follow-up study. Spinal Cord. 2017;55:285-9.

27. Moshi H, Sundelin G, Sahlen KG, Sorlin A. Traumatic spinal cord injury in the north-east Tanzania-describing incidence, etiology and clinical outcomes retrospectively. Glob Health Action. 2017;10:1355604.

28. Haisma JA, van der Woude LH, Stam HJ, Bergen MP, Sluis TA, Post MW, et al. Complications following spinal cord injury: occurrence and risk factors in a longitudinal study during and after inpatient rehabilitation. J Rehabil Med. 2007;39:393-8.

29. New PW. Secondary conditions in a community sample of people with spinal cord damage. J Spinal Cord Med. 2016;39:665-70.

30. Brinkhof MW, Al-Khodairy A, Eriks-Hoogland I, Fekete C, Hinrichs T, Hund-Georgiadis M, et al. Health conditions in people with spinal cord injury: Contemporary evidence from a population-based community survey in Switzerland. J Rehabil Med. 2016;48:197-209.

31. World Health Organization. International classification of functioning, disability and health - ICF. Geneva; 2001.

32. Noonan V, Kopec J, Mâsse L, Dvorak M. Measuring participation among persons with spinal cord injury: comparison of three instruments. Top Spinal Cord Inj Rehabil. 2010;15:49-62.

33. Borg J. Assistive technology, human rights and poverty in developing countries. Perspective based on a study in Banladesh, in Social Medicine and Global Health. Lund University: Lund, Helsingborg and Malmo; 2011.

34. Deconinck $H$. The health condition of spinal cord injuries in two Afghan towns. Spinal Cord. 2003;41:303-9.

35. Bickenbach J, Bodine C, Brown D, Burns A, Campbell R, Cardenas D, et al. International perspectives on spinal cord injury. Geneva: World Health Organization and ISCoS; 2013.

36. Borg J, Lindstrom A, Larsson S. Assistive technology in developing countries: national and international responsibilities to implement the Convention on the Rights of Persons with Disabilities. Lancet. 2009;374:1863-5.

37. Gosselin RA, Coppotelli C. A follow-up study of patients with spinal cord injury in Sierra Leone. Int Orthop. 2005;29:330-2.

38. Singh R, Dhankar SS, Rohilla R. Quality of life of people with spinal cord injury in Northern India. Int $\mathrm{J}$ Rehabil Res. 2008;31:247-51.

39. Kalyani HH, Dassanayake S, and Senarath U. Effects of paraplegia on quality of life and family economy among patients with spinal cord injuries in selected hospitals of Sri Lanka. Spinal Cord. 2015;53:446-50.

40. Nahar N, Nuri MRP, Mahmud I. Financial aid for the rehabilitation of individuals with spinal cord injuries in Bangladesh. DCID. 2012;23.

41. Whitehurst DG, Engel L, Bryan S. Short Form health surveys and related variants in spinal cord injury research: a systematic review. J Spinal Cord Med. 2014;37:128-38.

42. Tasiemski T, Priebe M, Wilski M. Life satisfcation and life values in people with spinal cord injury living in three Asian countries: a multicultural study. J Spinal Cord Med. 2013;36:118-26.

43. Johnson RL, Gerhart KA, McCray J, Menconi JC, Whiteneck GG. Secondary conditions following spinal cord injury in a populationbased sample. Spinal Cord. 1998;36:45-50.

44. Hartoonian N, Hoffman JM, Kalpakjian CZ, Taylor HB, Krause $\mathrm{JK}$, Bombardier $\mathrm{CH}$. Evaluating a spinal cord injury-specific model of depression and quality of life. Arch Phys Med Rehabil. 2014;95:455-65.

45. Muller R, Peter C, Cieza A, Geyh S. The role of social support and social skills in people with spinal cord injury-a systematic review of the literature. Spinal Cord. 2012;50:94-106.

46. Schimmack U, Radhakrishnan P, Oishi S, Dzokoto V, Ahadi S. Culture, personality, and subjective well-being: integrating process models of life satisfaction. J Pers Soc Psychol. 2002;82:582-93.

47. Tsutsumi A, Izutsu T, Akramul Islam MD, Amed JU, Nakahara S, Takagi F, et al. Depressive status of leprosy patients in Bangladesh: association with self-perception of stigma. Lepr Rev. 2004;75:57-66. 